\title{
PROPOSED METHODOLOGY FOR BUILDING-SPECIFIC EARTHQUAKE LOSS ASSESSMENT INCLUDING COLUMN RESIDUAL AXIAL SHORTENING
}

\author{
Ahmed Elkady', Gerard Güell², Dimitrios G. Lignos ${ }^{3}$ \\ ${ }^{1}$ Faculty of Engineering and Physical Sciences, University of Southampton, Southampton, United Kingdom \\ ${ }^{2}$ Risk Modelling Associate, Swiss Re Group, Zürich, Switzerland \\ ${ }^{3}$ Resilient Steel Structures Laboratory (RESSLab), École Polytechnique Fédérale de Lausanne (EPFL), \\ Lausanne, Switzerland
}

This paper proposes methodological developments for quantifying the impact of residual axial shortening of firststory steel columns on earthquake loss estimations in steel moment-resisting frame (MRF) buildings. A new formulation is proposed that accounts for the likelihood of having to demolish a steel MRF building due to column residual axial deformations in addition to residual story-drift ratios. The formulation is informed by means of data from a comprehensive survey conducted worldwide to assess the likelihood of steel column repairability due to residual axial shortening. A practical method for quantifying column axial-shortening in parametrized system-level numerical simulations is presented. The proposed approach is illustrated by conducting economic seismic loss estimations in two case-study steel MRF buildings designed in urban California according to the current seismic design practice. It is found that when the ground-motion duration is appreciable, the examined steel MRFs are more prone to column axial-shortening than residual story-drifts at moderate to high seismic intensities. The results suggest that economic losses due to demolition may be underestimated if column residual axial-shortening is neglected from loss estimations. Limitations as well as directions for future research are discussed.

\section{KEY WORDS}

Residual deformations; Seismic risk; Building demolition; Column axial shortening; Building-specific loss assessment.

\section{INTRODUCTION}

Experimental evidence (MacRae et al. 2009; Suzuki and Lignos 2015; Ozkula et al. 2017; Elkady and Lignos 2018a; Cravero et al. 2019) and field observations from past earthquakes (Saatcioglu et al. 2013; NILIM 2016) suggest that first-story steel columns in capacity-designed moment-resisting frame (MRF) buildings may experience nonlinear geometric instabilities at modest lateral drift demands. In turn, these may cause column axial-shortening $\left(\Delta_{\text {axial }}\right)$ and flange distortion $\left(\delta_{f}\right)$ as illustrated in

Figure 1a for a wide-flange steel column. These instability modes are strongly influenced by the geometric properties of the steel column along with the cumulative inelastic damage that it experiences during a seismic event (MacRae et al. 2009; Elkady and Lignos 2018b). Elkady and Lignos (2018a) demonstrated that the evolution of column axialshortening (and the associated flange distortion) is loading-history dependent (see

Figure 1b). Particularly, lateral loading histories comprising a large number of inelastic cycles (e.g., long-duration ground motions) could potentially result into an appreciable amount of column residual axial-shortening even at modest lateral drift demands (e.g., $2 \%$ to $3 \% \mathrm{rad}$ ). This issue has raised concerns regarding the steel MRF column repairability in the aftermath of earthquakes (Cravero et al. 2019). For instance,

Figure 1c shows that at a story-drift of $3 \%$, a W14x61 column subjected to cyclic lateral loading experiences column axial shortening of $30 \mathrm{~mm}$ and a flange distortion of $40 \mathrm{~mm}$. At the same lateral drift demand, the column's flexural strength is reduced to $30 \%$ of its maximum strength, $M_{\max }$. The 4-axes plot is termed repairability curve as introduced by Cravero et al. (2019) for a number of column cross-sections and different loading scenarios. Although the emphasis of the present paper is on steel structures, a similar challenge is manifested in reinforced concrete (RC) MRFs due to the associated RC beam elongation under cyclic loading (Fenwick and Megget 1993; Henry et al. 2017). From a governmental and (re-) insurance standpoint, the above challenges potentially have economic and social impacts (Stevenson et al. 2017). Therefore, such local engineering demand parameters (EDPs) should be prognosticated with sufficient accuracy. 

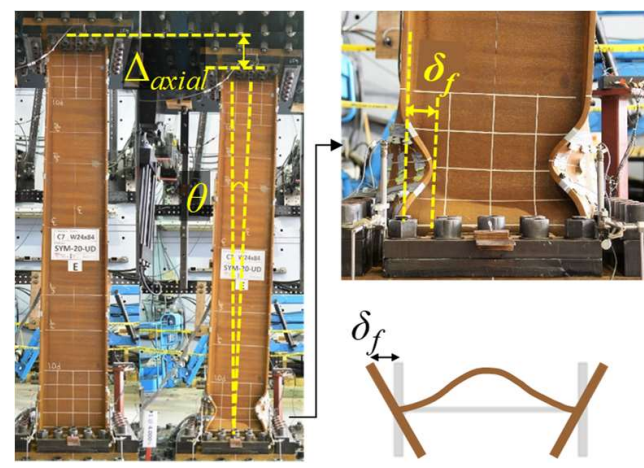

(a)

Residual flexural Strength $\left[\% M_{\max }\right]$

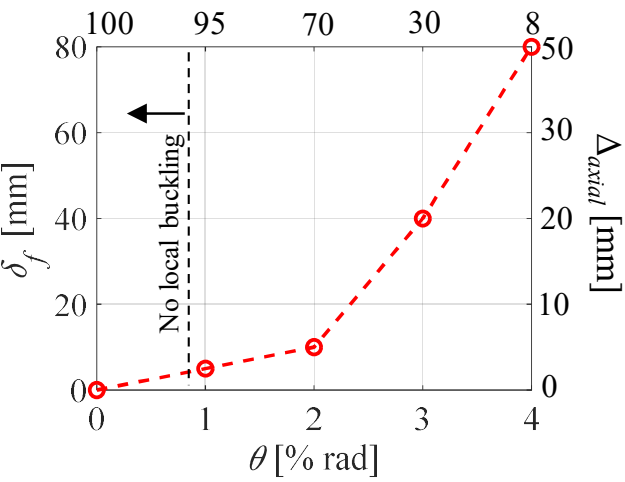

(c) inevitable.
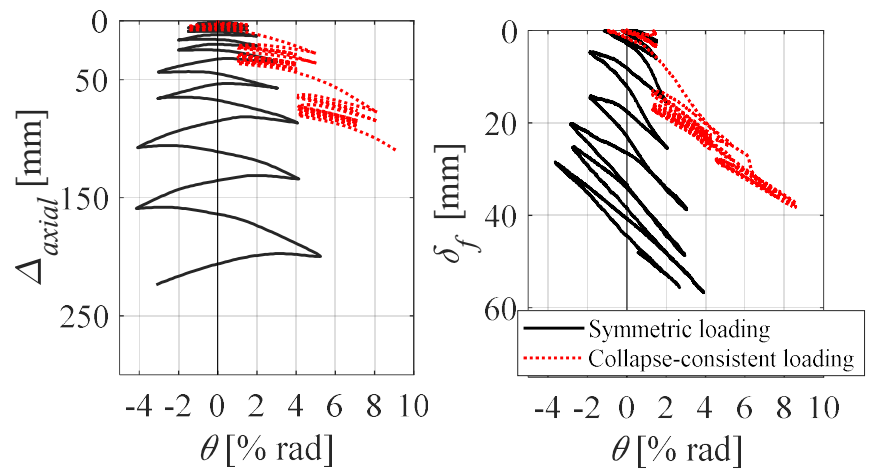

(b)

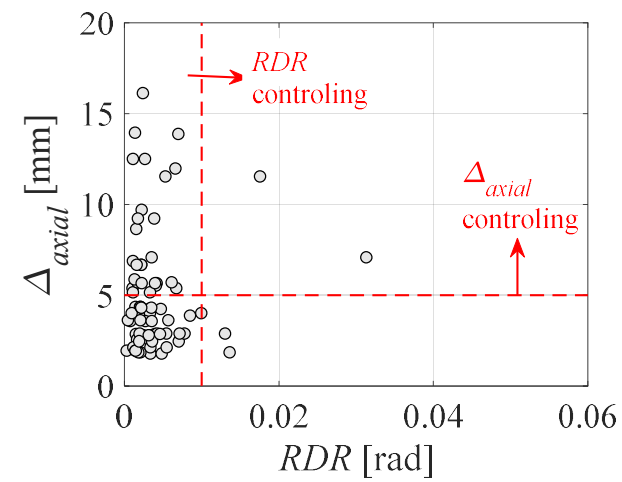

(d)

While deterioration models that enable explicit quantification of column axial-shortening have evolved (Suzuki and relationship between column axial shortening, lateral residual deformations and building demolition has not been

In a recent study, Suzuki and Lignos (2017) developed a fiber-based model for steel columns that efficiently traces the residual axial shortening due to local buckling-induced softening. Suzuki and Lignos (2019) used this model in Figure $1 \mathrm{~d}$ depicts the first-story column residual axial-shortening $\left(\Delta_{\text {axial }}\right)$ versus the maximum lateral residual storydrift ratio $(R D R)$ in an 8-story steel MRF, subjected to 40 long-duration seismic records. Chiefly, the first-story column base experiences appreciable axial shortening without considerable lateral residual deformations along the steel MRF height. Depending on the amount of $\Delta_{\text {axial }}$, floor tilting may occur (Suzuki 2018), and building demolition may be

Figure 1. (a) Steel column axial shortening (Elkady and Lignos 2018a); (b) evolution of column axialshortening and flange distortion [data from Elkady and Lignos (2018a)]; (c) sample reparability curve for a W14x61 column subjected to cyclic lateral loading [data from Cravero et al. (2019)]; (d) residual column axial-shortening versus residual story-drift ratio of an 8-story steel MRF under long-duration ground motions [data from Suzuki and Lignos (2019)].

Building-specific loss assessment methodologies underscore the significance of lateral residual deformations in earthquake-induced loss estimation of frame structures (FEMA 2012; Ramirez and Miranda 2012; Hutt et al. 2016; Hwang and Lignos $2017 \mathrm{a}, \mathrm{b})$. Prior studies have investigated the sensitivity of loss computations on the selected intensity measures (Kohrangi et al. 2016) as well as the employed nonlinear modeling assumptions of the respective frame structures (Hwang and Lignos 2017a, b). To the best of the authors' knowledge, none of the available building- 
specific loss estimation methodologies properly considers local EDPs (e.g., column axial shortening) that could ultimately result into building demolition.

This paper proposes a methodology to properly account for local EDPs that could adjudge a building irreparable regardless of the respective residual story-drifts in the aftermath of earthquakes; thus, demolition may be necessary. Although the emphasis is on steel MRF buildings, the methodology is generally applicable to other structural systems conditioned that appropriate data and component fragility functions are made available. Statistical results are presented based on a survey that was conducted to comprehend when a steel column within a steel MRF may be deemed irreparable. A practical way to estimate column residual axial-shortening is demonstrated. Finally, using two casestudy steel buildings designed to current practice, it is shown that when column residual axial-shortening is disregarded from building-specific loss estimations, demolition losses may be appreciably underestimated at given seismic intensities of interest to the profession.

\section{PROPOSED BUILDING-SPECIFIC LOSS ESTIMATION METHODOLOGY}

Under a given seismic intensity, a building can experience "Collapse" (C) due to increasing lateral drift demands. In the case of no-collapse (NC), "Demolition" (D) may be imperative due to large residual deformations that render a building irreparable. In the case of no-collapse and no-demolition (ND), "Repairs" (R) may be necessary due to structural and non-structural component damage. The above three events are mutually exclusive and collectively exhaustive. In turn, the total expected monetary losses arising from these events, conditioned on a given intensity measure (IM), $E\left[\mathrm{~L}_{\mathrm{T}} \mid \mathrm{IM}\right]$, may be quantified based on Eq. (1) (Krawinkler and Miranda 2004; Aslani and Miranda 2005; Ramirez and Miranda 2012):

$$
\begin{aligned}
& E\left[L_{T} \mid I M\right]=E\left[L_{T} \mid C\right] \cdot P(C \mid I M)+E\left[L_{T} \mid N C \cap D\right] \cdot P(D \mid N C, I M) \cdot P(N C \mid I M)+E\left[L_{T} \mid N C \cap R, I M\right] \\
& P(R \mid N C, I M) \cdot P(N C \mid I M)
\end{aligned}
$$

in which, $E\left[\mathrm{~L}_{\mathrm{T}} \mid \mathrm{C}\right]$ is the expected loss due to collapse; $E\left[\mathrm{~L}_{\mathrm{T}} \mid \mathrm{NC} \cap D\right]$ is the expected loss due to demolition when collapse did not occur; and $E\left[\mathrm{~L}_{\mathrm{T}} \mid \mathrm{NC} \cap R\right]$ is the expected loss due to repairs when collapse did not occur; $P(\mathrm{C} \mid \mathrm{IM})$ and $P(\mathrm{NC} \mid \mathrm{IM})$ are the probabilities of collapse and no-collapse, respectively at a given $\mathrm{IM} ; P(D \mid N C, \mathrm{IM})$ and $P(R \mid N C, \mathrm{IM})$ are the probabilities of demolition and repair, respectively, given no collapse at a given IM. In general terms, the probability of building demolition given no-collapse at a given IM, $P(D \mid N C$, IM), is quantified by integrating the demolition fragility function, $P(D \mid E D P)$, over the probability density function of the controlling $E D P$, $P(E D P \mid N C, \mathrm{IM})$. Losses due to demolition, $E\left[\mathrm{~L}_{\mathrm{D}} \mid \mathrm{IM}\right]$, are then calculated as the product of the probability of demolition times the cost of demolishing and constructing a new building; simply noted herein as "Cost". FEMAP58 (FEMA 2012) evaluates losses due to demolition by only considering the $R D R$ as expressed in Equation (2). Hence, the demolition fragility function, $P(D \mid R D R)$, is univariate. Let us assume that this is a lognormal cumulative distribution function $(\mathrm{CDF})$ with a median, $\mu_{R D R}$, representing the limiting value that prompts demolition and a standard deviation, $\sigma_{\ln R D R}$, representing the uncertainty in this limiting value.

Figure 2 shows a univariate demolition fragility function based on typical a mean and standard deviation reported in Ramirez and Miranda (2012).

$P(D \mid N C, I M)=\int_{0}^{\infty} P(D \mid R D R) d P(R D R \mid N C, I M)$

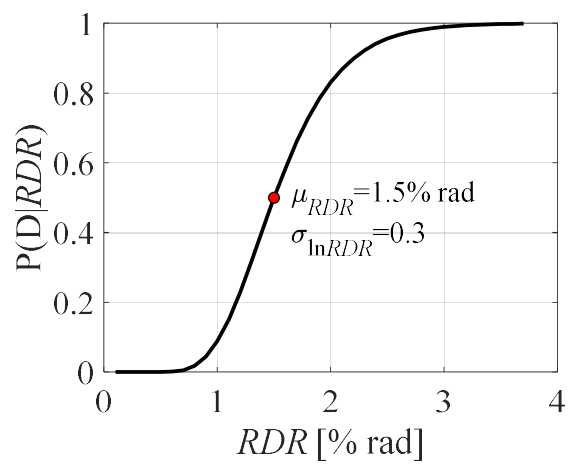


Figure 2. Typical univariate demolition fragility as a function of $R D R$.

Equation (2) does not depict the influence of column residual axial-shortening $\left(\Delta_{\text {axia }}\right)$ on the potential losses due to building demolition. Thus, Equation (3) is proposed for this purpose, in which, $P\left(R D R, \Delta_{\text {axial }} \mid N C, I M\right)$ is the probability of experiencing a certain $R D R$ and $\Delta_{\text {axial }}$ levels in a building that has not collapsed at a given IM, and $\mathrm{P}\left(\mathrm{D} \mid R D R, \Delta_{\text {axial }}\right)$ is the bivariate demolition fragility function; that is the probability of having to demolish the building conditioned on $R D R$ and $\Delta_{\text {axial }}$.

$P(D \mid N C, I M)=\int_{0}^{\infty} \int_{0}^{\infty} P\left(D \mid R D R, \Delta_{\text {axial }}\right) \cdot d P\left(R D R, \Delta_{\text {axial }} \mid N C, I M\right)$

To develop this bivariate demolition CDF, let us assume that the joint probability density function, $f\left(\mathrm{D} \mid R D R, \Delta_{\text {axial }}\right)$ in Equation (4) is lognormal. This hypothesis is evaluated later on. In this case, $\mu_{R D R}$ and $\mu_{\Delta a x i a l}$ are the central tendencies (median) of the lognormally distributed variables $R D R$ and $\Delta_{\text {axial }}$ (representing the limits for prompting demolition), respectively; $\sigma_{\ln R D R}$ and $\sigma_{\ln \triangle a x i a l}$ are the standard deviations of the normally distributed variables $\ln R D R$ and $\ln \Delta_{\text {axial }}$, respectively; $\rho$ is the population product-moment correlation coefficient of $\ln R D R$ and $\ln \Delta_{\text {axial }}$. A sample bivariate demolition PDF with arbitrary parameters is shown in Figure 3a.

$f\left(D \mid R D R, \Delta_{\text {axial }}\right)=\frac{1}{2 \pi \cdot R D R \cdot \Delta_{\text {axial }} \cdot \sigma_{\operatorname{lnRDR}} \cdot \sigma_{\ln \Delta_{\text {axial }}} \sqrt{1-\rho^{2}}} \cdot e^{-\frac{q}{2}}$

in which, $q=\frac{1}{1-\rho^{2}} \cdot\left[\left(\frac{\ln (R D R)-\mu_{R D R}}{\sigma_{\ln R D R}}\right)^{2}-2 \rho\left(\frac{\ln (R D R)-\mu_{R D R}}{\sigma_{\ln R D R}}\right)\left(\frac{\ln \left(\Delta_{\text {axial }}\right)-\mu_{\Delta_{\text {axial }}}}{\sigma_{\ln \Delta_{\text {axial }}}}\right)+\left(\frac{\ln \left(\Delta_{\text {axial }}\right)-\mu_{\Delta_{\text {axial }}}}{\sigma_{\ln \Delta_{\text {axial }}}}\right)^{2}\right]$

The bivariate CDF for demolition can then be obtained by integrating the PDF. This integration is not analytically attainable (Yue 2002); thus, it is numerically achieved. In particular, the cumulative probability of demolition, under a given pair of $E D P$ values $\left(R D R_{i}\right.$ and $\left.\Delta_{\text {axial }, i}\right)$, is deduced by integrating under the PDF surface as illustrated in Figure $3 \mathrm{~b}$. The deduced bivariate demolition CDF is shown in

Figure $3 \mathrm{c}$. In this figure, it is worth highlighting that when $\Delta_{\text {axial }}$ is zero, the demolition fragility function reverts to the univariate function of $R D R$ shown earlier in

Figure 2. The same holds true with respect to $\Delta_{\text {axial }}$ when $R D R$ is zero.

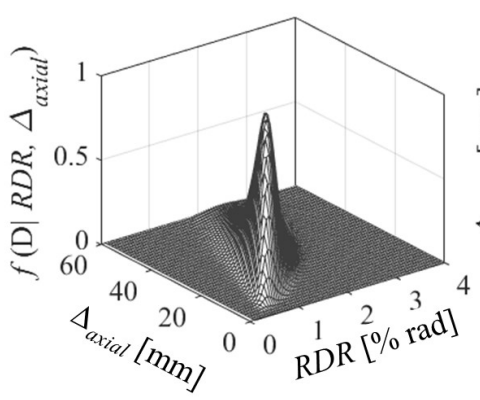

(a) bivariate PDF surface

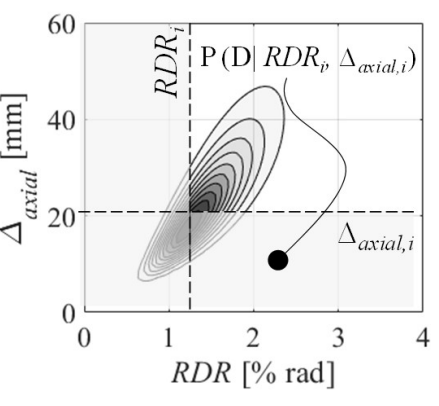

(b) bivariate PDF contours

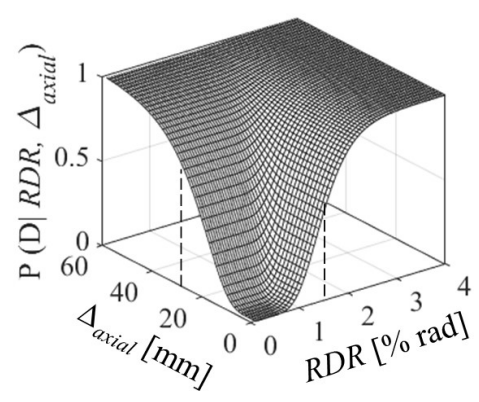

(c) bivariate CDF surface

Figure 3. Bivariate demolition fragility function.

To evaluate Equations (3) and (4), multiple parameters should be computed. These include the population parameters of the individual univariate demolition fragility functions; that is $\mu_{R D R}, \mu_{\triangle a x i a l}, \sigma_{\ln R D R}$ and $\sigma_{\ln \Delta a x i a l}$, in addition to the correlation coefficient, $\rho$. These are deduced herein based on a conducted international survey, as discussed in the following section. Moreover, the same population parameters need to be deduced for the $R D R$ and $\Delta_{\text {axial }}$ values representing the engineering demand at a given IM. These story-based and local EDPs can be quantified by means of system-level nonlinear response-history analyses as discussed in the subsequent sections. 


\section{Population Parameters of the Bivariate Demolition Fragility Function}

The population parameters of the individual demolition fragility functions, $P(\mathrm{D} \mid R D R)$ and $P\left(\mathrm{D} \mid \Delta_{\text {axial }}\right)$, depend on the building's use/lateral load system typology/material, regional practices as well as engineering judgment. In essence, these parameters represent the $R D R$ and $\Delta_{\text {axial }}$ limits that dictate whether it is sensible and economically efficient to repair a building in the aftermath of an earthquake. Prior studies (Iwata et al. 2006; McCormick et al. 2008; Ramirez and Miranda 2012) indicate that a limiting $\mu_{R D R}$ value suggesting demolition, may range from $0.5 \%$ to $1.5 \%$. These values are typically associated with a standard deviation, $\sigma_{\ln R D R}$ of 0.30 . On the other hand, the dependency of building demolition on the column axial-shortening has never been scrutinized. For this reason, the authors conducted an international survey (Güell et al. 2018) to quantify rational $\Delta_{\text {axial }}$ limits that may prompt demolition in steel frame buildings (i.e., irreparable column damage due to cross-sectional local buckling) in conjunction with $R D R$. The surveyed individuals were provided with "repairability curves" that combine in a single plot the column axial shortening and flange distortion deformation amplitudes along with the column's residual flexural capacity as a function of story-drift demands (Cravero et al. 2019). The statistics from the collected survey responses are summarized in

Figure 4.
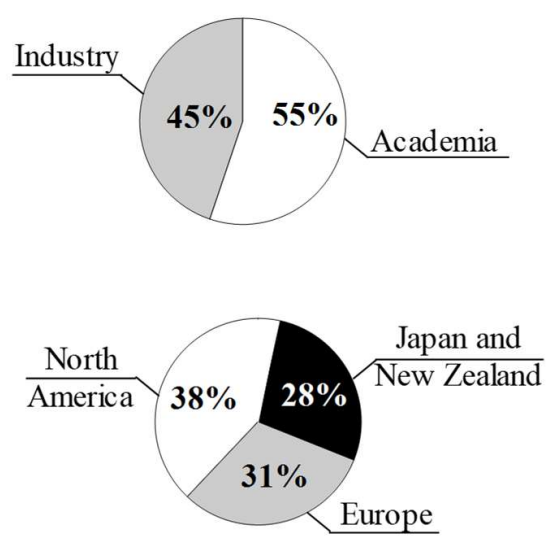

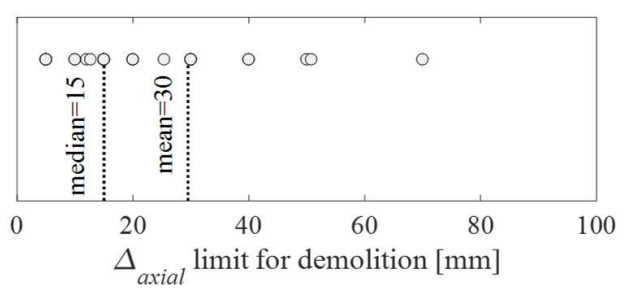

\begin{tabular}{lccccc}
\hline Region & $\begin{array}{c}\mu_{\Delta a x i a l} \\
{[\mathrm{~mm}]}\end{array}$ & $\sigma_{\ln \Delta a x i a l}$ & $\begin{array}{c}\mu_{R D R} \\
{[\% \mathrm{rad}]}\end{array}$ & $\sigma_{\ln R D R}$ & $\rho_{D}$ \\
\hline North America & 24 & 0.45 & 1.10 & 0.25 & 0.25 \\
\hline Europe & 11 & 0.64 & 0.96 & 0.33 & 0.62 \\
\hline Japan and New Zealand & 10 & 0.69 & 0.58 & 0.37 & 0.69 \\
\hline
\end{tabular}

Figure 4. Summary of the conducted survey's responses on the $\Delta_{\text {axial }}$ limit for demolition.

In brief, the survey comprises 33 responses from leading engineering practitioners and academics in America, Europe, Asia and the South Pacific. The reported $\Delta_{\text {axial }}$ limit ranged from $5 \mathrm{~mm}$ to $75 \mathrm{~mm}$. This variation was lognormally distributed, based on a standard K-S test (Kolmogorov 1933; Smirnov 1939) at a 5\% significance level, with a central tendency, $\mu_{\Delta a x i a l}=15 \mathrm{~mm}$. This central tendency is further categorized by region. In particular, responses from Japan and New Zealand were the most conservative indicating a median $\Delta_{\text {axial }}$ of $10 \mathrm{~mm}$ and a standard deviation, $\sigma_{\mathrm{ln} \Delta a x i a l}$, of 0.69 . On the other hand, responses from North America revealed a median of $24 \mathrm{~mm}$ and a standard deviation of 0.45 . The univariate fragility functions for $\Delta_{\text {axial }}$, based on the deduced fragility parameters per region, are plotted in Figure 5a. To the best of the author's knowledge, this data is considered to be unique.

The respondents were also asked for the $R D R$ limit that prompts demolition. The reported values are summarized in Figure 4 as well as the correlation coefficient between the natural logarithm of the reported $R D R$ and $\Delta_{\text {axial }}$ demolition limits, noted as $\rho_{D}$. In summary, responses from North America, Europe, Japan and New Zealand had median $R D R$ values, $\mu_{R D R}$, of $1.10 \%, 0.96 \%$ and $0.58 \%$, respectively. These responses suggest that in high seismicity countries (i.e., Japan and New Zealand) more conservative residual deformation limits may be expected. The univariate fragility functions for $R D R$, based on the deduced fragility parameters per region, are plotted in Figure $5 \mathrm{~b}$. 


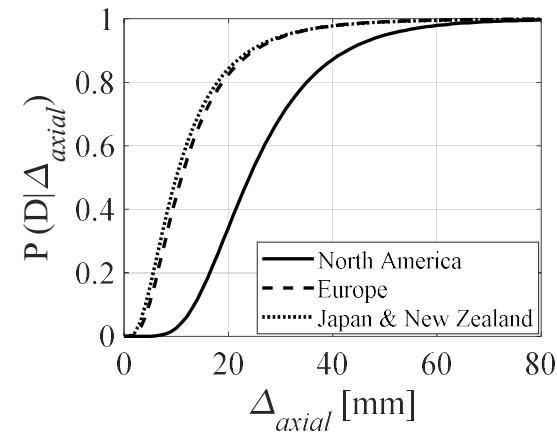

(a)

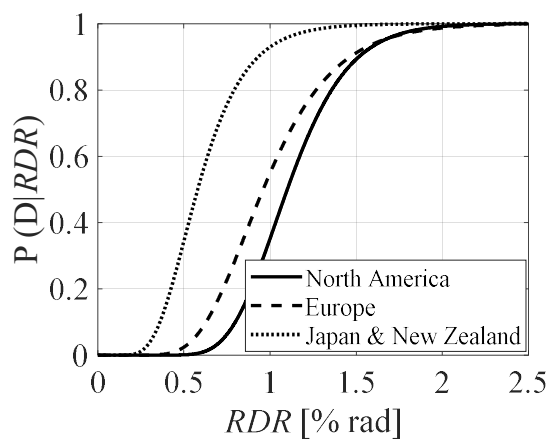

(b)

Figure 5. Univariate demolition fragilities as a function of $\Delta_{\text {axial }}$ based on the conducted survey.

\section{Computation of Column Residual Axial Shortening}

The computation of residual story drifts along a building's height is well established (Ruiz-García and Miranda 2006; Hwang and Lignos 2018). However, the computation of column axial-shortening is not trivial. It typically requires the use of high-fidelity nonlinear building models that explicitly capture buckling-induced softening in steel columns under cyclic loading. These could either be continuum finite-element models (Elkady and Lignos $2018 \mathrm{~b}$; Wu et al. 2018) or fiber-based models with effective stress-strain formulations that trace softening over a buckling length (e.g. Suzuki and Lignos 2017). Non-local formulations have also been proposed (Kolwankar et al. 2018) to tackle the issue of spurious mesh dependency in stress-strain formulations with softening (Pijaudier-Cabot and Bažant 1987). Alternatively, empirical formulations can facilitate the computation of $\Delta_{\text {axial }}$ of a steel column (MacRae et al. 2009; Elkady and Lignos 2018b). These formulations rely on geometric parameters and column plastic-rotation demands, thereby still allowing the use of phenomenological models in large-scale parametrized nonlinear simulations. Equation (5) provides such an expression as proposed by Elkady and Lignos (2018b).

$\Delta_{\text {axial }}[\mathrm{mm}]=13.62 \sum \theta_{p l}^{1.596}\left(\frac{h}{t_{w}}\right)^{0.769}\left(1-\frac{P_{g}}{P_{y}}\right)^{-1.819},\left(R^{2}=0.873\right)$

The formulation depends on the cumulative plastic rotation $\left(\Sigma \theta_{p l}\right)$ a column experiences for a given loading history, the column web slenderness ratio $\left(h / t_{w}\right.$; where $h$ is the web depth and $t_{w}$ is the web thickness) and the applied gravity - induced axial load ratio $\left(P_{g} / P_{y}\right.$; where $P_{g}$ is the gravity-induced axial load and $P_{y}$ is the column's axial yield strength).

Figure 6a shows the predicted $\Delta_{\text {axial }}$ for a steel column experiment conducted by the first and third author in prior work (Elkady and Lignos 2018a).

Alternatively, fragility functions for steel columns may be used where column axial-shortening damage states $\left(D S_{i}\right)$ are expressed as a function of a given $E D P$.

Figure 6b shows such an example (Elkady et al. 2018a). However, it should be noted that these functions do not consider the influence of cumulative damage on the respective $\Delta_{\text {axial }}$, which is strongly dependent to the ground motion characteristics. 


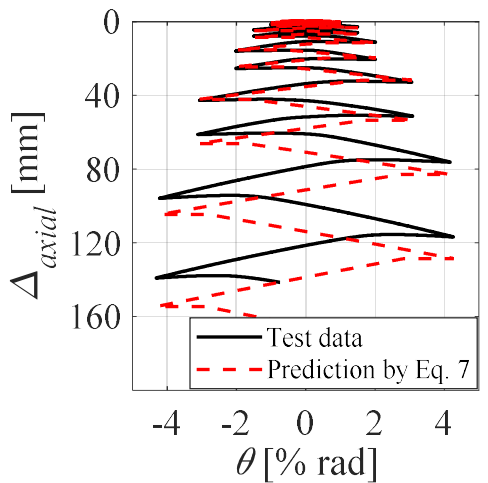

(a)

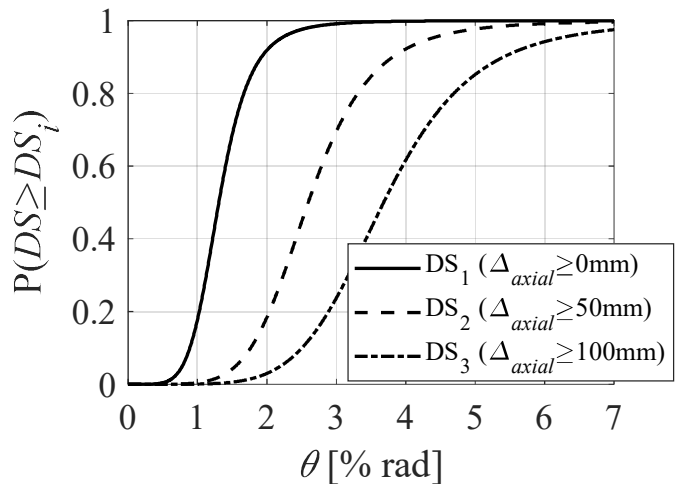

(b)

Figure 6. (a) Comparison of predicted and measured column axial-shortening; (b) Sample fragility functions for column axial-shortening damage states $\left[h / t_{w}=35\right.$ and $\left.P_{g} / P_{y}=0.25\right]$ (Elkady et al. 2018a)

\section{Computation of Correlation Between the EDPs}

The population product-moment correlation coefficient (Pearson coefficient) between the natural logartithmic values of the lateral residual drift demands and the column residual axial shortening (i.e., global and local EDPs of interest), noted as $\rho_{E D P}$, can be simply computed based on the available building simulation data through comprehensive nonlinear response history analyses. A detailed discussion of these computations is provided in the subsequent section based on the analyzed case-study buildings.

\section{CASE STUDY BUILDINGS AND NONLINEAR MODELS}

In this section, the potential implications of considering column residual axial-shortening in building-specific loss estimations is investigated. Two case-study buildings are used for this purpose. These buildings, which represent the current design practice in North America, have a rectangular plan view shown in

Figure 7. They are designed with perimeter special moment frames (SMFs) according to ANSI/AISC 341-10 (AISC 2010) and ASCE/SEI 7-10 (ASCE 2010) in urban California. Steel columns are idealized as fixed at the ground level. Design details along with the seismic performance assessment of the buildings can be found in prior studies by the first and third authors (Elkady and Lignos 2014, 2015).

Two-dimensional (2D) numerical models of the buildings in the East-West (EW) loading direction are developed in the OpenSees simulation platform (Mckenna 1997). Point plastic-hinge models are employed to represent the nonlinear behavior of structural components. The point plastic hinges, which are assigned at pre-defined locations of anticipated inelasticity, comprise the modified Ibarra-Medina-Krawinkler deterioration model (Ibarra et al. 2005; Lignos and Krawinkler 2011) for both beams and columns. Deterioration model parameters for steel columns are computed based on modeling procedures discussed in Lignos et al. (2019). Whereas deterioration parameters of steel beams are computed with empirical formulations proposed by Lignos and Krawinkler (2011). These have been adjusted to properly capture the composite action effects (Elkady and Lignos 2014). The gravity framing system is explicitly considered herein based on the modeling approach discussed in Elkady and Lignos (2015) in lieu of experimental and numerical findings (Gupta and Krawinkler 2000; Flores et al. 2014; Elkady and Lignos 2015; Del Carpio Ramos et al. 2019) highlighting the stabilizing effects of the gravity system on the seismic response of steel buildings. Besides, the gravity framing consideration as part of the $2 \mathrm{D}$ building model has direct implications on earthquake-induced loss computations (Hwang and Lignos 2017a, b). The first-mode period, $T_{1}$, of the 4- and 8-story buildings in the EW loading direction is 1.25 and $1.72 \mathrm{sec}$, respectively, based on standard eigenvalue analysis. Viscous damping is considered based on the Rayleigh damping model based on the procedure outlined in Zareian and Medina (2010). Two percent damping ratio $(\xi=2 \%)$ is assumed at the first and third modes of the case study buildings. 
Gravity framing
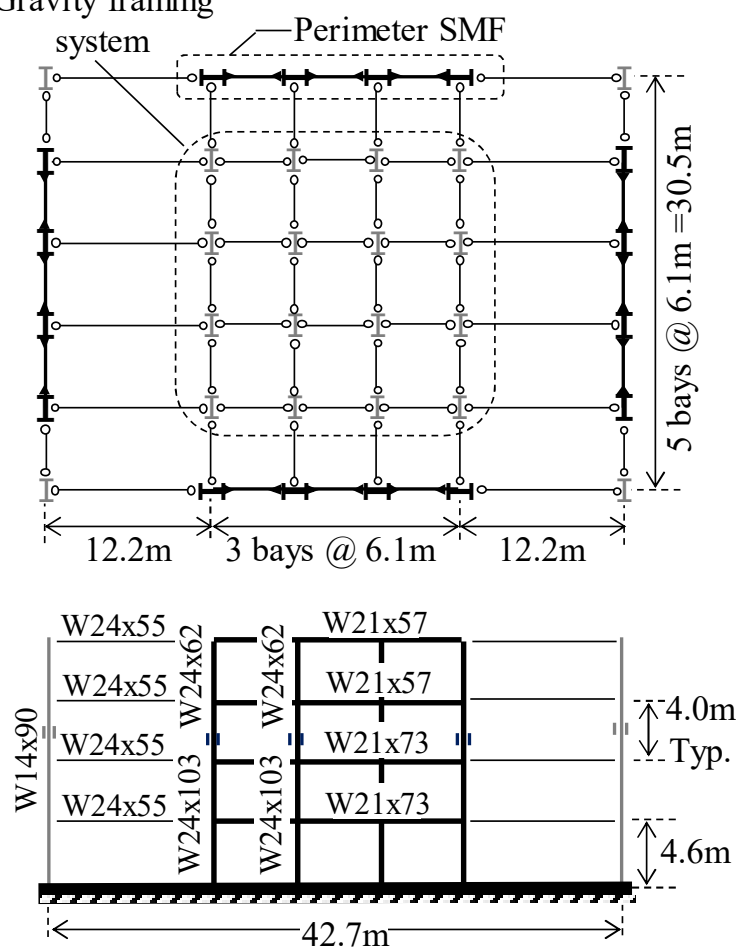

$\underline{\text { Seismic Design Parameters }}$

Structural System: Steel SMF

Location: Los Angeles, CA $\left(34.000^{\circ},-118.150^{\circ}\right)$

Risk Category: II (Office)

Importance Factor: 1.0

Seismic Design Category: D

Soil Class: D

\section{Structural components}

I Wide-flange gravity column

$\mapsto$ Wide-flange column

$\Delta$ Fully-restrained RBS connection

o Conventional shear-tab connection

I I Column splice

Figure 7. Plan view and elevation of the analyzed 4-story case study building.

\section{GROUND MOTION SETS FOR NONLINEAR RESPONSE HISTORY ANALYSES}

Figure 8a shows the design-basis (DBE) and maximum-considered earthquake (MCE) absolute acceleration response spectra for the building location as per ASCE (2016). At MCE, the first-mode spectral acceleration ordinates of the 4and 8 -story buildings correspond to $0.90 \mathrm{~g}$ and $0.55 \mathrm{~g}$, respectively. A short- and long-duration ground motion set (noted henceforth as the SD and LD sets, respectively) are considered. These sets were compiled by Chandramohan et al. (2016). Each set comprises 73 horizontal record pairs (146 individual records). The two sets are distinguished by the effective duration, $D s(5 \% \sim 75 \%)$. Records within the LD set have an effective duration larger than 25 seconds. Each of the LD records has a spectrally-matched SD record; an illustrative comparison is shown in

Figure 8 b. Referring to

Figure $8 \mathrm{a}$, the median spectra of the two ground motion sets confirms the above observations. The two ground motion sets are used herein in comparative nonlinear response-history analyses to isolate and quantify the influence of ground motion duration on the steel MRF column residual axial-shortening but not to form conclusions on the collapse risk of the case-study buildings under consideration. It should be noted that in this spectral matching procedure, the SD records were scaled by factors ranging from 0.34 to 5.0. These scaling factor magnitudes are reasonable, hence, bias in structural response can be considered as fairly limited (Dávalos and Miranda 2019a, b). 


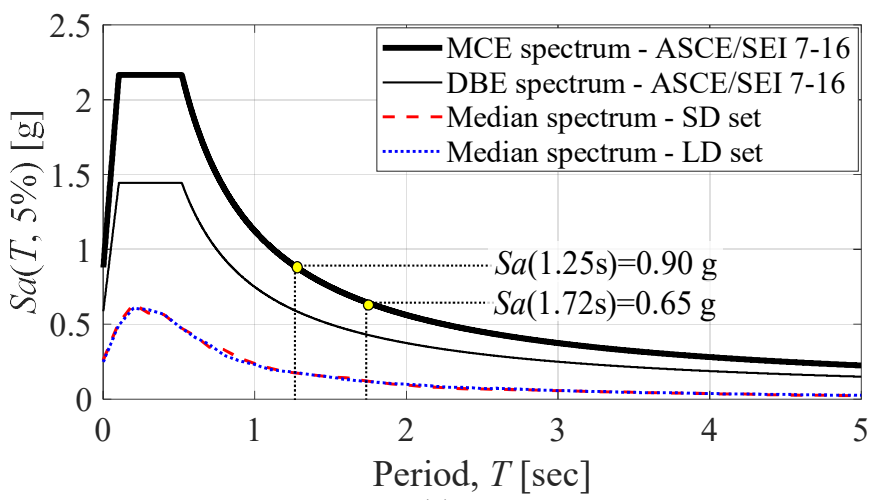

(a)

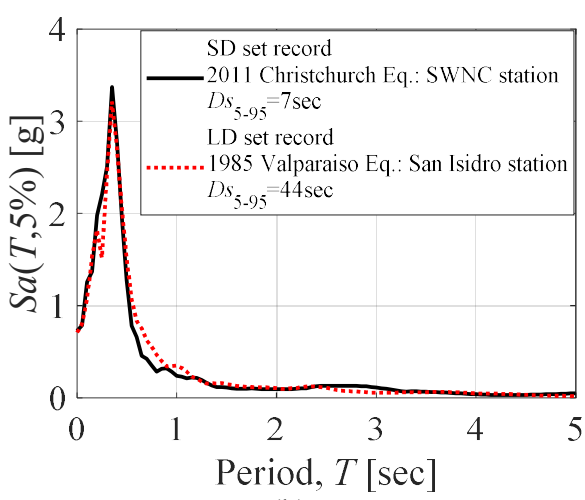

(b)

Figure 8. (a) Comparison between DBE and MCE spectra at the design location as per ASCE/SEI 7-16 and the median spectra of the SD and LD sets; (b) comparison of the elastic response spectra of two spectrallymatched earthquake records.

\section{NONLINEAR BUILDING SIMULATIONS AND DISCUSSION}

Incremental dynamic analysis (IDA) (Vamvatsikos and Cornell 2002) is conducted by scaling each ground motion record till it causes structural collapse. Record scaling is done with respect to the 5\%-damped average spectral acceleration, $S a_{a v g}$ within a period range of $0.2 T_{1}$ to $3 T_{1}$. This IM is suggested in prior related studies (Eads et al. 2015; Kohrangi et al. 2016) in an effort to reduce the influence of the record-to-record variability on the structural response.

Figure 9 summarizes typical IDA results for the 4-story building under the SD set for a range of $E D P$ s of interest including the peak story-drift ratio $(S D R)$, the peak absolute floor acceleration $(P F A)$, the residual story-drift ratio $(R D R)$ and the column residual axial shortening $\left(\Delta_{\text {axial }}\right)$. In the same figure, the median, $16^{\text {th }}$ and $84^{\text {th }}$ percentile curves are superimposed based on counted statistics to get a sense of the record-to-record variability on the $E D P$ s of interest. Equation (5) is used to compute the expected $\Delta_{\text {axial }}$ in the first-story steel MRF columns due to local buckling.

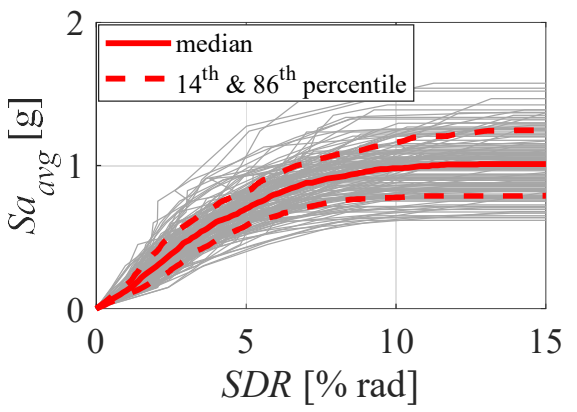

(a)

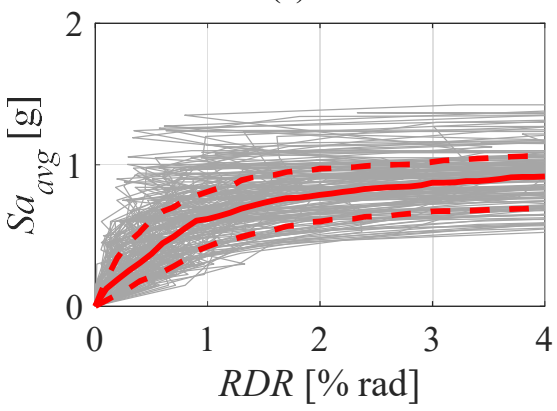

(c)

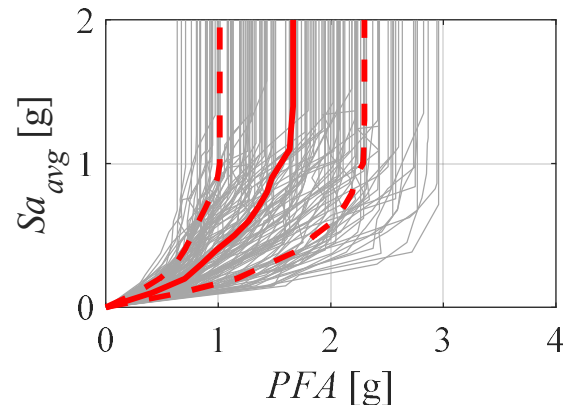

(b)

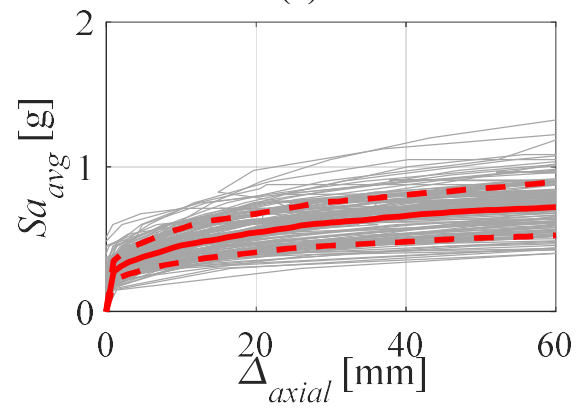

(d)

Figure 9. IDA curves for the 4-story building subjected to the SD set. 
Figure 9a indicates that the collapse capacity of the 4-story steel frame building is nearly $1 \mathrm{~g}$ with a standard deviation of 0.21 . Notably, the record-to-record variability is fairly small due to the IM selection as expected (Eads et al. 2015; Kohrangi et al. 2016).

Figure $9 \mathrm{~b}$ depicts the expected saturation of $P F A$ demands once the 4-story building becomes inelastic. However, damage in acceleration-sensitive non-structural components should still be expected even at low to moderate seismic intensities (Aslani and Miranda 2005).

Figure 9c shows the progression of $R D R$ with respect to IM. A large variability in $R D R$ values is observed under different ground-motion records. This observation is consistent with prior studies (Ruiz-García and Miranda 2006; Hwang and Lignos 2018).

Figure 9d suggests that column axial-shortening is fairly minor under SD records scaled at seismic intensities lesser than the DBE. However, at higher intensities, first-story columns experience inelastic rotation demands; hence, axial shortening increases exponentially due to the progression of web local buckling particularly in deep columns (Ozkula et al. 2017; Elkady and Lignos 2018a).

The median IDA curves of the 4-story building based on the SD and LD sets are compared in Figure 10. At spectral ordinates associated with DBE (i.e., $\left.S a_{a v g}=0.44 \mathrm{~g}\right)$ or $\mathrm{MCE}\left(S a_{a v g}=0.67 \mathrm{~g}\right)$, differences in median $R D R$ values are insignificant (less than $10 \%$ ) between the two ground motion sets. Conversely, the impact of ground-motion duration on $\Delta_{\text {axial }}$ is evident. In particular, the median $\Delta_{\text {axial }}$ values under the SD set are about five times smaller than those under the LD set. This is attributed to the ground-motion duration that imposes large cumulative plastic-rotation demands on the first-story steel MRF columns.

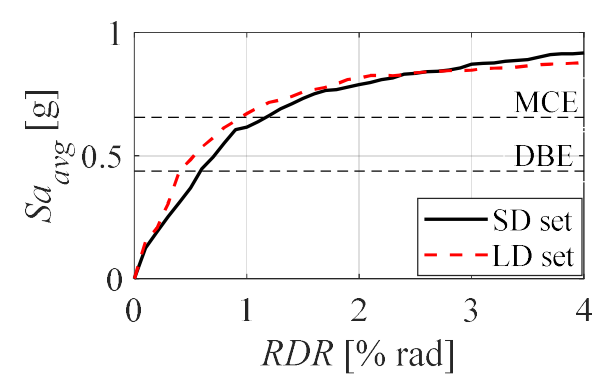

(a)

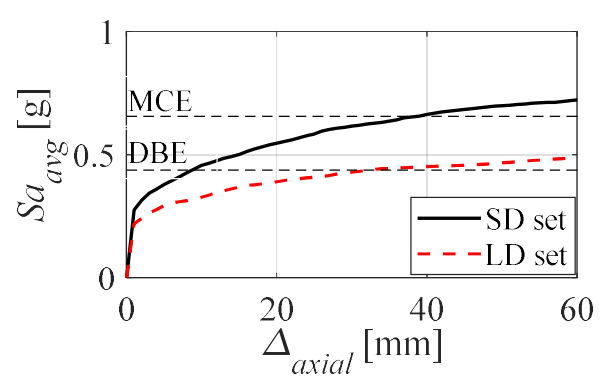

(b)

\section{Figure 10. Comparison between median IDA curves for the 4-story building when subjected to the SD and} LD sets.

Figure 11 depicts the above observations at discrete ground-motion intensities for the $E D P \mathrm{~s}$ of interest for the two case-study buildings. The general consensus is that story-based $E D P \mathrm{~s}(S D R \mathrm{~s}, P F A \mathrm{~s}, R D R \mathrm{~s})$ are somewhat dependent on the ground-motion type. Based on Figure 12, buildings subjected to LD records experience about $10 \%$ lower $S D R$ and PFA demands compared to SD records. A stronger effect is observed on $R D R$ where LD records result into $20 \%$ to $45 \%$ lower demands compared to SD records. Most importantly, the ground-motion duration has a profound influence on the residual axial-shortening in first-story columns. Notably, LD records result into four to six times larger $\Delta_{\text {axial }}$ than that obtained with SD records. This issue is more pronounced in the 4-story building since shortperiod buildings typically experience a much larger number of inelastic drift cycles compared to long-period ones (Krawinkler 1996; Suzuki and Lignos 2019).

The nonlinear response-history analyses results of the examined buildings suggest that while lateral residual deformations at MCE intensities may be fairly small $(\approx 0.5 \% \mathrm{rad})$ under the LD set, column residual axial-shortening is appreciable (larger than $10 \mathrm{~mm}$ and up to $\sim 60 \mathrm{~mm}$ ), thereby controlling losses due building demolition (see Figure $11 \mathrm{~b}, 8$-story building subjected to the LD set). Moreover, the influence of inelastic loading excursions during LD records tends to reduce the collapse capacity, $S a_{\text {collapse }}$, of the examined buildings by about $12 \%$ compared to that obtained based on SD records (see

Figure 11b). Prior studies (Raghunandan and Liel 2013; Chandramohan et al. 2016) on the collapse capacity of frame structures indicated a reduction from $20 \%$ to $50 \%$ due to ground motion duration. 
(a)

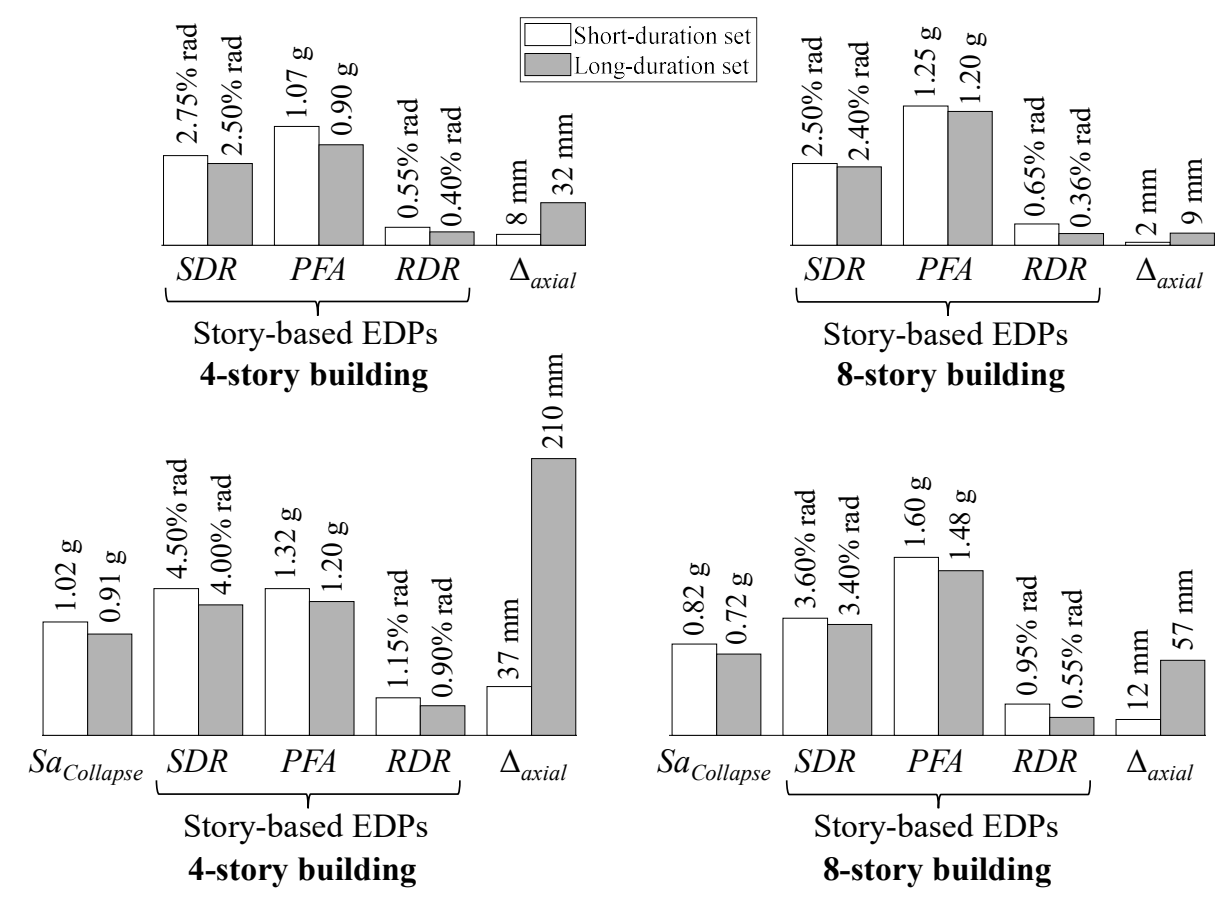

(b)

\section{Figure 11. Comparison of median EDPs of the 4- and 8-story case study buildings at: (a) DBE; and (b) MCE seismic intensities for $\mathrm{SD}$ and $\mathrm{LD}$ sets.}

Figure 12a shows the correlation coefficient between $R D R$ and $\Delta_{\text {axial }}$ of the 4-story building as a function of the seismic intensity, $S a_{a v g}$. For a given $S a_{a v g}$, the correlation is calculated between the residual deformation values deduced from the surviving ground-motion records (i.e., records that did not cause collapse at this seismic intensity). Based on this figure, the relation between $\rho_{E D P}$ and $S a_{a v g}$ follows more-or-less the same trend for both two ground motion sets. Below the median collapse capacity of the 4-story building, $S a_{\text {avg }}<1.0 \mathrm{~g}$, the correlation between the two quantities is fairly weak $\left(-0.25<\rho_{E D P}<0.25\right)$. This implies that a large $R D R$ does not necessarily imply a large $\Delta_{\text {axial }}$ and vice versa. This supports the argument to consider $\Delta_{\text {axial }}$ in the demolition loss formulation. At intensities higher than $S a_{\text {collapse }}$, the correlation increases. This can be attributed to the fact that at higher seismic intensities both residual deformation metrics tend to be large and systematically increase with $S a_{a v g}$. Moreover, due to the lesser number of survival records, the correlation increases. The observed fluctuations in the correlation values (e.g., see the sudden drop in $\rho_{E D P}$ at $S a_{a v g} \approx 1.5 \mathrm{~g}$ ) is mainly attributed to the sensitivity of the $R D R$ to record-to-record variability as well as the seismic intensity. While $\Delta_{\text {axial }}$ systematically increases when the seismic intensity increases, $R D R$ may experience strong fluctuations even within the same record, scaled at different intensities. Looking at two of the surviving records, scaled at $S a_{a v g}=1.5 \mathrm{~g}$, an increasing trend is observed in $\Delta_{\text {axial }}$ throughout the response history (see Figure 12c). On the other hand, although both records lead to large $S D R$ demands (i.e., $\sim 10 \%$ rad), the measured $R D R$ values are fairly different; Record 1 yields an $R D R$ of about $5.5 \%$ while Record 2 yields a modest $R D R$ value of $0.7 \%$. This phenomena, observed in Record 2, is often referred to as structural resurrection (Vamvatsikos and Cornell 2002). In this case, although the building underwent considerable lateral drift demands, the observed $R D R$ is fairly small. Same observations hold true for the 8-story case-study building but are not shown here due to brevity.

Following the above discussion, $\rho_{E D P}$, which is used to construct the joint probability function of the EDPs at a given $\mathrm{IM}$, is deduced based on the natural logarithmic values of the demand $R D R$ and $\Delta_{\text {axial }}$ values as shown in

Figure $12 \mathrm{~b}$. Note that in the logarithmic domain, the fluctuations in the $\rho_{E D P}$ values are somewhat filtered. Accordingly, curve-fitting may be used to characterize a continuous $\rho_{E D P}$-IM function for a more practical implementation in loss computations. 


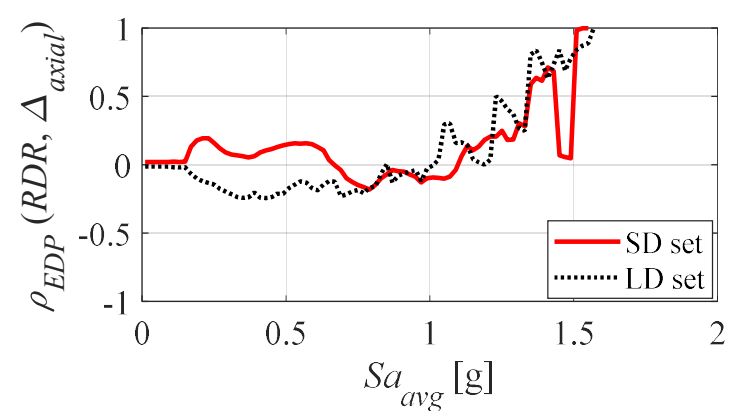

(a)

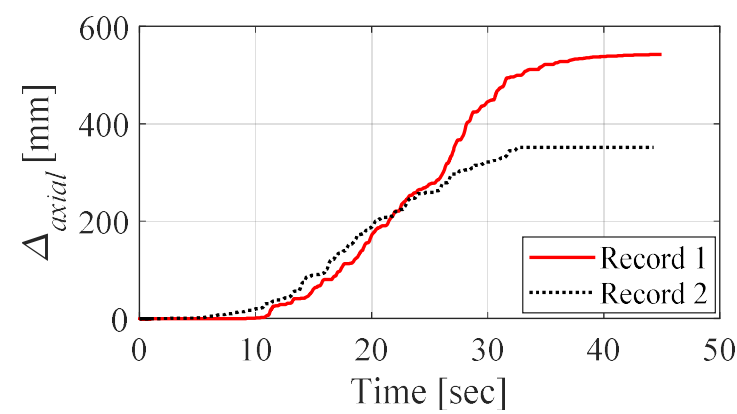

(c)

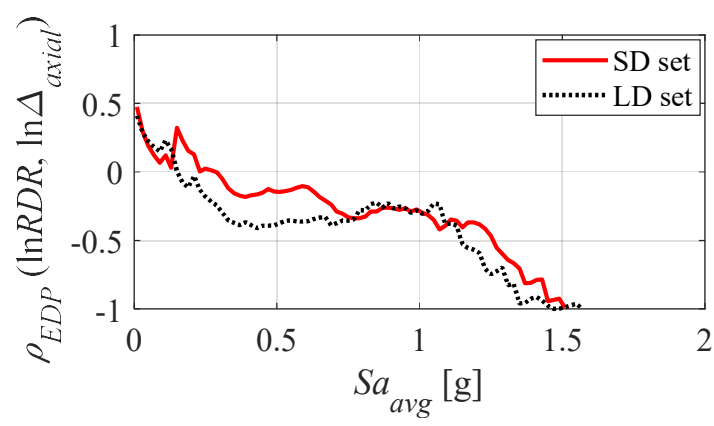

(b)

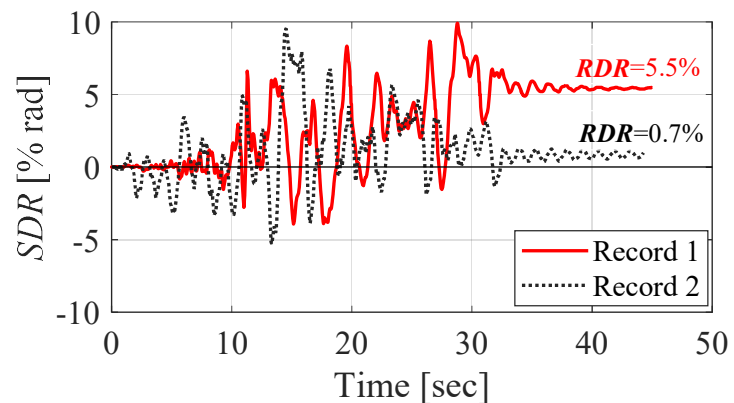

(d)

Figure 12. Pearson correlation coefficient, $\rho_{E D P}$, between the $R D R$ and $\Delta_{\text {axial }}$ values in the (a) normal and (b) logarithmic domains; sample time-histories of (c) $\Delta_{\text {axial }}$ and (b) SDR for two surviving ground-motion records scaled near collapse intensity.

\section{EXPECTED LOSSES WITH/WITHOUT COLUMN RESIDUAL AXIAL SHORTENING}

To get a sense of the influence of column residual axial-shortening on building earthquake losses, the methodology proposed in Section 2 is employed. Vis-à-vis the discussion in Section 4, emphasis is placed on the building seismic responses under the LD set. Two cases are considered as follows:

- Case 1: the building-specific loss assessment methodology proposed by Ramirez and Miranda (2012) is employed, which only considers the influence of residual story-drifts on losses due demolition. For the univariate demolition fragility function; a median residual drift-ratio of $1.1 \%$ is considered with a standard deviation value of 0.25 , representing the survey-reported values from North America (see Figure 5b).

- Case 2: the proposed loss assessment methodology outlined in Section 2 is employed; in which, $\Delta_{\text {axial }}$ is explicitly considered in addition to $R D R$. The population parameters of the $R D R$ demolition fragility are taken as in Case 1. The $\Delta_{\text {axial }}$ fragility function is constructed based on the survey responses from North America (see Figure 4). The correlation coefficient between the natural logarithmic values of the $R D R$ and $\Delta_{\text {axial }}$ limiting values is directly computed based on the survey's North American data; that is $\rho_{D}=0.24$.

The structural and non-structural building components, their assumed damage states and associated repair costs are similar to those summarized in Hwang and Lignos (2017a). Because FEMA P-58 (FEMA 2012) does not provide fragility functions for wide-flange steel columns, the ones proposed by Elkady et al. (2018a) are adopted herein. The assumed total replacement cost for demolition of the 4- and 8-story buildings is 14 and 28 million dollars (M\$), respectively. Building-specific loss assessment for Cases 1 and 2 are conducted with the software EaRL (Elkady et al. 2018 b). The discussion herein is facilitated based on detailed results from the 4-story building.

Figure 13 shows the corresponding vulnerability curves of the 4-story building in terms of normalized expected losses, $E[\mathrm{~L} \mid \mathrm{IM}]$, versus $S a_{a v g}$ for Cases 1 and 2. These curves are disaggregated into losses due to Collapse, Demolition and Repair. While

Figure 13a shows that in Case 1 demolition losses due to residual story-drifts become critical at $S a_{a v g} \approx 0.75 \mathrm{~g}$, 
Figure $13 \mathrm{~b}$ suggests that in Case 2 the expected loss due to demolition attains a peak at $S a_{a v g} \approx 0.5 \mathrm{~g}$ when the column residual axial-shortening is considered as a potential indicator for building demolition (i.e., Case 2). In turn, this augments the expected demolition loss since the probability of losses due to structural collapse is nearly zero at $S a_{\text {avg }} \approx 0.5 \mathrm{~g}$.

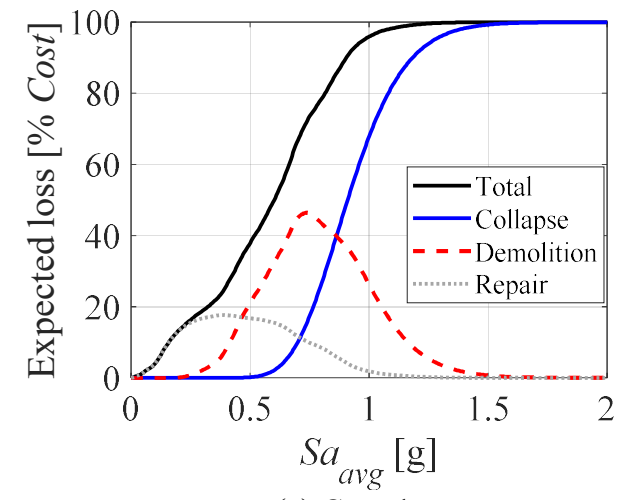

(a) Case 1

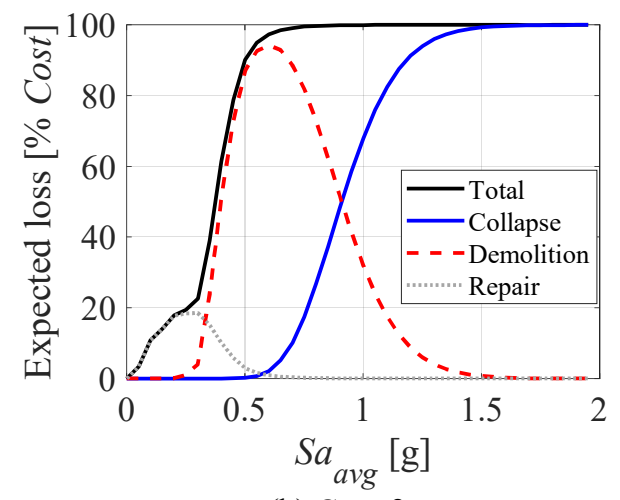

(b) Case 2

Figure 13. Expected normalized loss versus seismic intensity measure for the 4-story building- results based on LD set.

These observations are further exploited in

Figure 14 where losses are visualized at the DBE and MCE seismic intensities for both case-study buildings. In particular, according to Case 1, the expected losses at the DBE seismic intensity are controlled by repairs in structural and/or non-structural components for both buildings. Referring to

Figure 14, since first-story steel MRF columns experience local buckling due to the large number of inelastic cycles, even at modest lateral drift demands, the demolition loss may control if column residual axial-shortening is considered in the loss computations (i.e., Case 2). The results suggest that demolition losses represent at least $40 \%$ of the building replacement cost at the DBE intensity, regardless of the building height.

At seismic events with a low probability of occurrence (MCE),

Figure 14 suggests that losses due to demolition could be underestimated by at least $60 \%$ if column residual axialshortening is neglected in the loss computations. This is attributed to the fact that, at MCE, the examined case-study buildings experience fairly small residual drift-ratios along their height (i.e., less than $0.5 \%$ ) under the long-duration ground motion set.

(a)

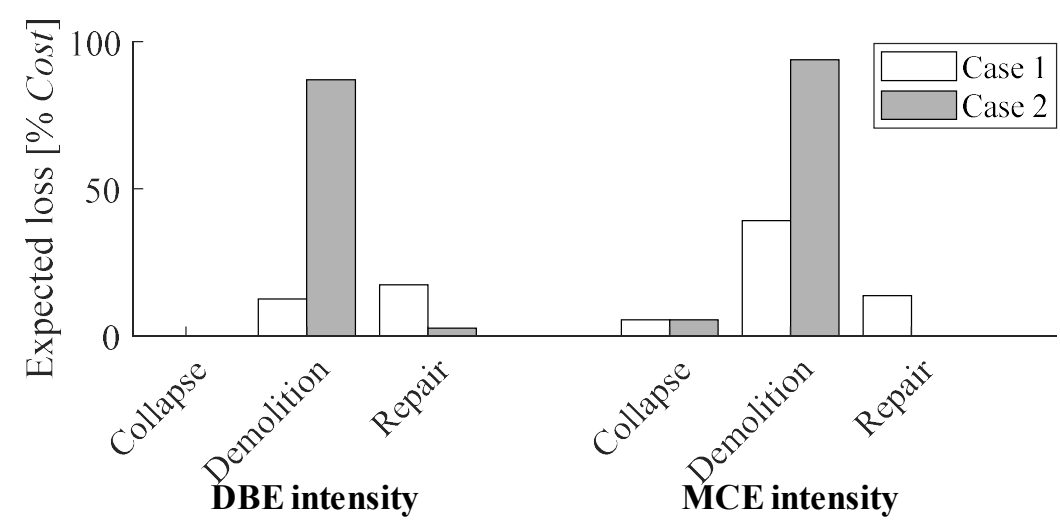


(b)

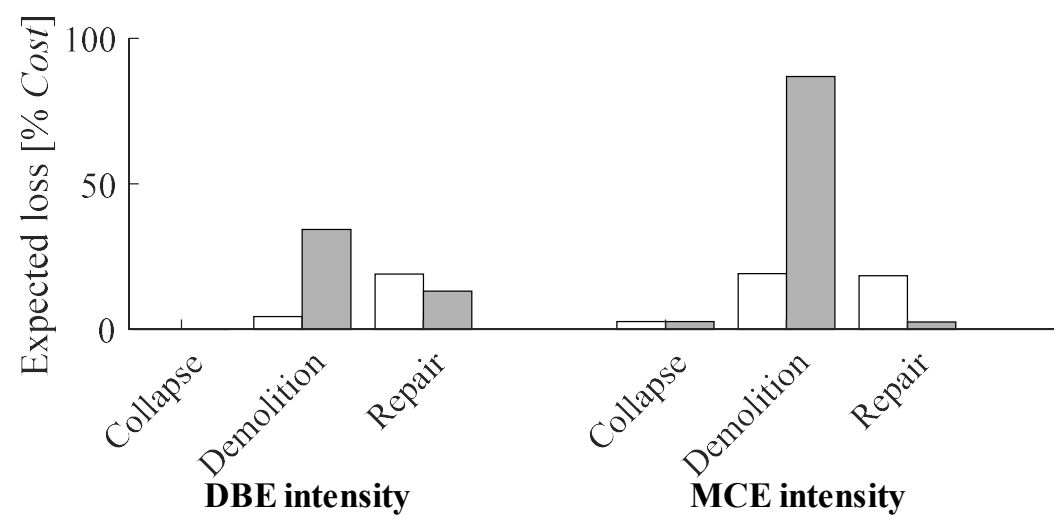

Figure 14. Breakdown of normalized expected losses for the (a) 4-story and (b) 8-story buildings at selected seismic intensities based on LD set.

\section{Influence of adopted fragility parameters on losses due to building demolition}

Intuitively, the assumed parameters that define the bivariate fragility function (see Equation 4) due to the residual story-drift and column axial-shortening have a profound effect on losses due to building demolition. Referring to Figure 4, these values may be fairly different for (a) the same structure, (b) community-critical structures, and (c) the design region. The sensitivity of the computed losses due demolition is quantified herein based on variations in the assumed bivariate demolition fragility function parameters of Eq. (4). Particularly, the demolition loss, normalized by the total replacement cost (Cost) is quantified for a range of paired $\mu_{R D R}$ and $\mu_{\Delta a x i a l}$ values. The standard deviation parameters and the correlation coefficient are assumed to be constant in such variations. The results are presented in the form of surface plots as shown in

Figure 15. The points representing the median parameters used in Section 5.2 (i.e., $\mu_{R D R}=1.1 \%$ rad and $\mu_{\Delta a x i a l}=24 \mathrm{~mm}$ ) are superimposed as a reference in the same figure.

In most cases, and particularly at MCE intensity (see

Figure $15 \mathrm{c}$ and $\mathrm{d}$ ), the variation in demolition loss is not considerable even when more generous (e.g., $\mu_{\Delta \text { axial }} \geq 25 \mathrm{~mm}$ ) fragility parameters are assumed. The modest variation in demolition loss with regards to the assumed fragility parameters can be inferred by the smooth surface slope. For instance, for the 4-story building, considering a $\mu_{\Delta a x i a l}$ value of $50 \mathrm{~mm}$, instead of $5 \mathrm{~mm}$, results in a $10 \%$ reduction in the expected losses due demolition. These observations are mainly attributed to the large vertical residual deformations measured in those cases $(210 \mathrm{~mm}$ and $57 \mathrm{~mm}$ in the 4 and 8 -story buildings, respectively). Hence, at such deformation amplitudes, the probability of demolition approaches unity (see

Figure 3c).

Contrary to the MCE intensity, when vertical and horizontal residual deformations are relatively small, the demolition loss can vary significantly based on the assumed fragility parameters. For instance, in the case of the 8-story building under the DBE intensity (see

Figure $15 \mathrm{~b}$ ), adopting a $\mu_{\Delta \text { axial }}$ value of $50 \mathrm{~mm}$ instead of $5 \mathrm{~mm}$ results in about $80 \%$ reduction in the expected demolition loss. The steep slope of the surface plot in this case also indicates that demolition loss may become appreciable (more than $50 \%$ contribution to total losses) only if the median fragility parameters are $\mu_{R D R} \leq 0.5 \%$ and/or $\mu_{\Delta a x i a l} \leq 15 \mathrm{~mm}$. In summary, these simple comparisons further demonstrate the importance of considering the "Demolition" event loss due to column residual axial shortening. 


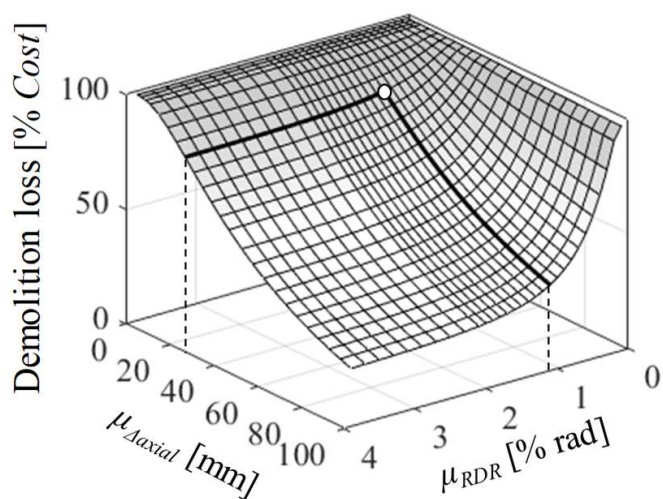

(a) 4-story building at DBE intensity

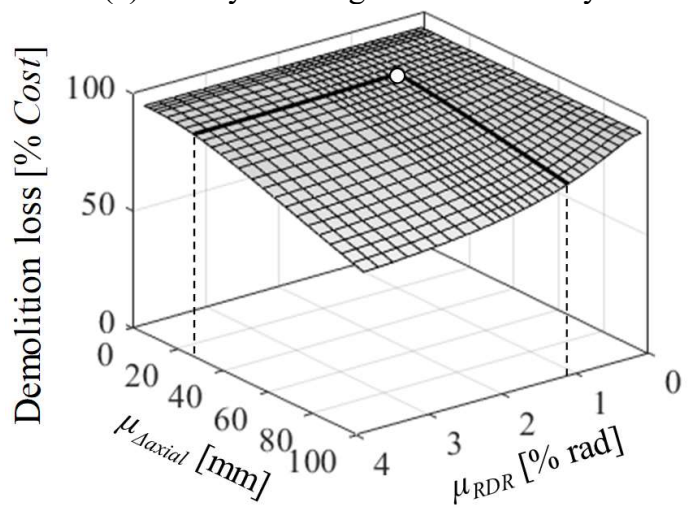

(c) 4-story building at MCE intensity

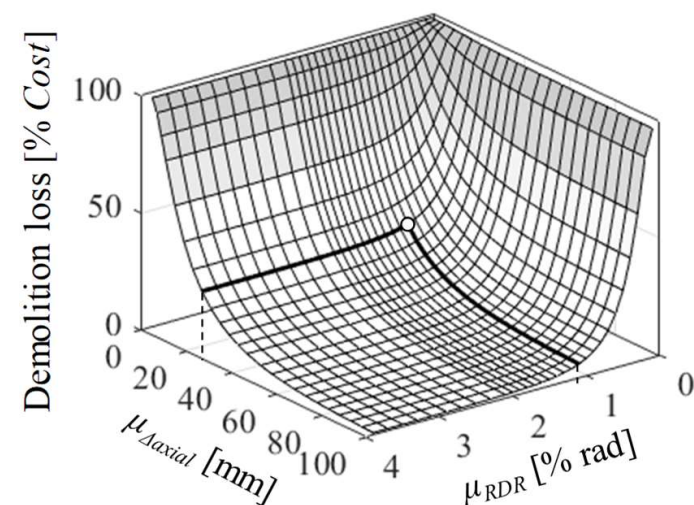

(b) 8-story building at DBE intensity

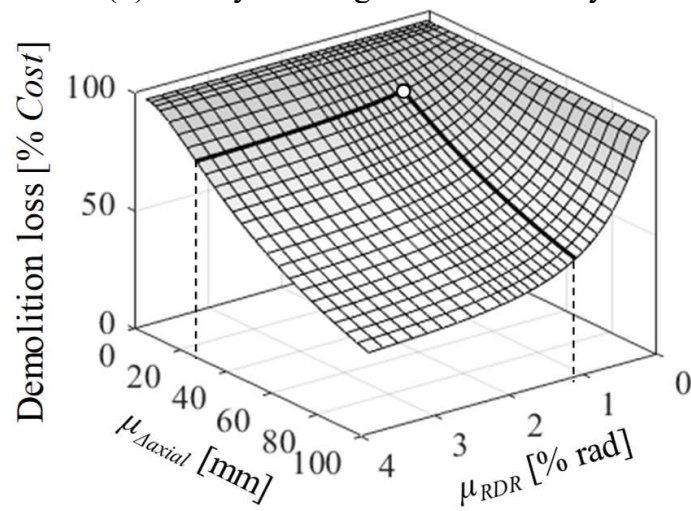

(d) 8-story building at MCE intensity

Figure 15. Variation in expected demolition losses with assumed median fragility parameters based on the LD set.

\section{LIMITATIONS OF THE PRESENT STUDY AND FUTURE WORK}

Despite the fact that the present work highlights the influence of a key local EDP, namely column residual axialshortening, that may control decisions associated with building demolition and/or structural repairs in the aftermath of earthquakes, a number of limitations along with avenues for future work are recognized in this section. In particular,

- All columns considered herein were assumed to be ideally fixed at the ground level. The inherent flexibility of exposed or embedded column base connections (Rodas et al. 2017) may significantly influence the column residual axial-shortening (Inamasu et al. 2019a, b).

- Field observations from past earthquakes (e.g., Clifton et al. 2011; Garini et al. 2015) along with numerical studies (Olarte et al. 2018) suggest that the inelastic behavior of columns in structures as well as bridge piers could be considerably affected by soil-structure-interaction, which was neglected in the present study.

- The paper findings suggest that recently proposed structural solutions (Freddi et al. 2017; Latour et al. 2019) may be further exploited to potentially minimize steel MRF column structural damage due to local buckling. This is likely to reduce the likelihood of building demolition due to column residual axial-shortening.

- Exploiting the benefits of controlled soil plastification (Anastasopoulos et al. 2010; Gelagoti et al. 2012) in prospective seismic designs may be an alternative to minimize column residual axial-shortening in steel MRFs. However, this shall be explored in a probabilistic manner within the Performance-based Earthquake Engineering framework (Cornell and Krawinkler 2000).

- As a simplification, the population parameters of the univariate demolition fragility function with respect to axial shortening are deduced in this study by weighting all experts' judgments, within the same geographical region, equally. Elaborate approaches, that use different weighing schemes while taking the expert's background into 
account (Jaiswal et al. 2012, Ioannou et al. 2017), can be exploited to deduce representative population parameters.

- Two, low and mid-rise case study buildings with special steel moment frames were investigated herein to quantify the column axial shortening and to demonstrate its potential influence on demolition loss estimations. The validity of the measured levels of axial shortening as well the observed trends and correlations should be further examined in various building geometries and structural typologies.

- The reported results are based on scaling of two spectrally matched ground-motion record sets up to the DBE and MCE intensities. Generally, such scaling procedures may result in physically unrealistic ground motions and may induce bias in structural response (Shome et al. 1998; Luco and Bazzurro 2007). Although the above issues were considered herein by limiting the magnitude of scaling and by using an efficient/sufficient intensity measure (i.e., $S a_{a v g}$ ), further investigations are encouraged using site-specific ground-motion records as well as main shockafter shock scenarios where column axial shortening may be pronounced.

\section{CONCLUSIONS}

Existing building-specific loss estimation methodologies only consider residual story-drifts $(R D R)$ when quantifying economic losses associated with building demolition. Experiments and field observations suggest that steel frame structures may be deemed to be demolished if local buckling-induced residual axial-shortening of first-story steel columns is appreciable in the aftermath of earthquakes. Parametrized nonlinear response history analyses of steel moment-resisting frame (MRF) systems subjected to large suites of ground-motion sets suggest that column axialshortening may be significant even at modest story-drift demands at least when the ground motion duration is significant.

This paper presents a new methodology that expands the current state-of-the-art on building specific-loss estimation (FEMA P-58, FEMA (2012); Ramirez and Miranda (2012)). The methodological developments take into account important local engineering demand parameters $(E D P \mathrm{~s})$, such as column residual axial-shortening, in addition to residual story-drift demands, to compute the likelihood that a steel frame building should be demolished after a seismic event. Accordingly, we proposed a bivariate demolition function that combines both aspects controlling demolition, namely $R D R$ and column residual axial shortening, $\Delta_{\text {axial }}$. The population parameters of this function were established by means of a survey, which was conducted worldwide. Methods to compute the column axial shortening in systemlevel nonlinear response history analyses were also presented.

Two case-study steel MRF buildings designed according to today's seismic design practice were examined to exploit the differences in forced building demolition on vulnerability curves, when column residual axial shortening is considered in economic loss estimations. The case-study buildings were subjected to a large suite of spectrallymatched short- and long-duration seismic records. While in the former, building demolition is controlled by residual story-drifts, in the latter both the 4- and 8-story buildings experienced fairly small residual story-drift demands $(R D R<0.5 \% \mathrm{rad})$ but considerable column residual axial shortening $\left(\Delta_{\text {axial }}>10 \mathrm{~mm}\right)$ at modest lateral drift demands. Hence, conventional building-specific loss estimation methodologies may underestimate the demolition loss by more than $60 \%$ if $\Delta_{\text {axial }}$ is neglected in the loss computations.

The proposed methodological framework could facilitate the systematic quantification of the influence of the physical mechanisms of soil-structure-interaction on loss quantification. The benefits of low damage technologies for column base connections could be further exploited by means of seismic life-cycle analysis.

\section{ACKNOWLEDGEMENTS}

This study was based on work supported by the Swiss National Science Foundation (Award Number 200021_169248) as well as internal funding from École Polytechnique Fédérale de Lausanne (EPFL). The financial support is gratefully acknowledged. The authors would like to sincerely thank Prof. Reagan Chandramohan, of University of Canterbury, and Profs. Jack W. Baker and Gregory G. Deierlein, of Stanford University, for sharing the two ground motion sets used in this study. The authors would also like to extend their appreciation to all academics and practitioners who contributed to the online survey. Any opinions, findings, and conclusions or recommendations expressed in this paper are those of the authors and do not necessarily reflect the views of sponsors.

\section{REFERENCES}


AISC. Seismic provisions for structural steel buildings. Chicago, IL2010 ;ANSI/AISC 341-10.

Anastasopoulos, I., Gazetas, G., Loli, M., Apostolou, M., and Gerolymos, N. Soil failure can be used for seismic protection of structures. Bulletin of Earthquake Engineering 2010; 8(2), 309-326.

ASCE. Minimum design loads for buildings and other structures. Reston, VA. 2010; ASCE/SEI 7-10.

ASCE. Minimum design loads ans associated criteria for buildings and other structures. Reston, VA. 2016; ASCE/SEI $7-16$.

Aslani, H., and Miranda, E. Probabilistic earthquake loss estimation and loss disaggregation in buildings. The John A. Blume Earthquake Engineering Center, Stanford Univeristy, CA 2005; Report No. 157.

Chandramohan, R., Baker, JW., and Deierlein, GG. Quantifying the influence of ground motion duration on structural collapse capacity using spectrally equivalent records. Earthquake Spectra 2016; 32(2), 927-950.

Clifton, C., Bruneau, M., MacRae, G., Leon, R., and Fussell, A. Steel structures damage from the christchurch earthquake series of 2010 and 2011. Bulletin of the New Zealand Society for Earthquake Engineering 2011; 44(4), 297-318.

Cornell, CA., and Krawinkler, H. Progress and challenges in seismic performance assessment. PEER Center News $2000 ; 3(2), 1-3$.

Cravero, J., Elkady, A., and Lignos, DG. Experimental evaluation and numerical modeling of wide-flange steel columns subjected to constant and variable axial load coupled with lateral drift demands. ASCE Journal of Structural Engineering 2019 (accepted).

Dávalos, H., and Miranda, E. Evaluation of bias on the probability of collapse from amplitude scaling using spectralshape-matched records. Earthquake Engineering \& Structural Dynamics 2019a; 48(8), 970-986.

Dávalos, H., and Miranda, E. Evaluation of the scaling factor bias influence on the probability of collapse using sa(t1) as the intensity measure. Earthquake Spectra 2019b; 35(2), 679-702.

Del Carpio Ramos, M., Mosqueda, G., and Lignos, DG. Experimental investigation of steel building gravity framing systems under strong earthquake shaking. Soil Dynamics and Earthquake Engineering 2019; 116, 230-241.

Do, TN., and Filippou, FC. A damage model for structures with degrading response. Earthquake Engineering \& Structural Dynamics 2018; 47(2), 311-332.

Eads, L., Miranda, E., and Lignos, DG. Average spectral acceleration as an intensity measure for collapse risk assessment. Earthquake Engineering \& Structural Dynamics 2015; 44(12), 2057-2073.

Elkady, A., Ghimire, S., and Lignos, DG. Fragility curves for wide-flange steel columns and implications on buildingspecific earthquake-induced loss assessment. Earthquake Spectra 2018a; 34(3), 1405-1429.

Elkady, A., Hwang, S-H., and Lignos, DG. Earl: Toolbox for earthquake risk and loss assessment of building assets. Proc., $16^{\text {th }}$ European Conference on Earthquake Engineering (ECEE), Thessaloniki, Greece $2018 \mathrm{~b}$.

Elkady, A., and Lignos, DG. Modeling of the composite action in fully restrained beam-to-column connections: implications in the seismic design and collapse capacity of steel special moment frames. Earthquake Engineering \& Structural Dynamics 2014; 43(13), 1935-1954.

Elkady, A., and Lignos, DG. Effect of gravity framing on the overstrength and collapse capacity of steel frame buildings with perimeter special moment frames. Earthquake Engineering \& Structural Dynamics 2015; 44(8), 12891307. 
Elkady, A., and Lignos, DG. Full-scale testing of deep wide-flange steel columns under multi-axis cyclic loading: Loading sequence, boundary effects and out-of-plane brace force demands. ASCE Journal of Structural Engineering 2018a; 144(2): 04017189.

Elkady, A., and Lignos, DG. Improved seismic design and nonlinear modeling recommendations for wide-flange steel columns. ASCE Journal of Structural Engineering 2018b; 144(9): 04018162.

FEMA. Seismic performance assessment of buildings. Federal Emergency Management Agency, Washington, DC, 2012; Report FEMA P-58-1.

Fenwick, RC., and Megget, LM. Elongation and load deflection characteristics of reinforced concrete members containing plastic hinges. Bulletin of the New Zealand National Society for Earthquake Engineering 1993; 26(1), 2841.

Flores, FX., Charney, FA., and Lopez-Garcia, D. Influence of the gravity framing system on the collapse performance of special steel moment frames. Journal of Constructional Steel Research 2014; 101, 351-362.

Freddi, F., Dimopoulos, C., and Karavasilis, T. Rocking damage-free steel column base with friction devices: design procedure and numerical evaluation. Earthquake Engineering \& Structural Dynamics 2017, 46(14), 2281-2300.

Garini, E., Gazetas, G., and Anastasopoulos, I. 3-dimensional rocking and sliding case histories in the 2014 cephalonia, greece earthquakes. Proc., $6^{\text {th }}$ International Conference on Earthquake Geotechnical Engineering, Christchurch, New Zealand 2015; 1-4.

Gelagoti, F., Kourkoulis, R., Anastasopoulos, I., and Gazetas, G. Rocking isolation of low-rise frame structures founded on isolated footings. Earthquake Engineering \& Structural Dynamics 2012; 41(7), 1177-1197.

Güell, G., Elkady, A., and Lignos, DG. Assessment of column repairabilty following earthquakes. 2018, $<$ https://www.surveymonkey.com/r/8QLSDJZ>.

Gupta, A., and Krawinkler, H. Behavior of ductile smrfs at various seismic hazard levels. ASCE Journal of Structural Engineering 2000; 126(1), 98-107.

Henry, RS., Dizhur, D., Elwood, KJ., Hare, J., and Brunsdon, D. Damage to concrete buildings with precast floors during the 2016 kaikoura earthquake. Bulletin of the New Zealand Society for Earthquake Engineering 2017; 50(2), 174-186.

Hutt, CM., Almufti, I., Willford, M., and Deierlein, G. Seismic loss and downtime assessment of existing tall steelframed buildings and strategies for increased resilience. ASCE Journal of Structural Engineering 2016; 142(8): C4015005.

Hwang, S-H., and Lignos, DG. Nonmodel-based framework for rapid seismic risk and loss assessment of instrumented steel buildings. Engineering Structures 2018; 156, 417-432.

Hwang, S-H., and Lignos, DG. Earthquake-induced loss assessment of steel frame buildings with special moment frames designed in highly seismic regions. Earthquake Engineering \& Structural Dynamics 2017a; 46(13), $2141-2162$.

Hwang, S-H., and Lignos, DG. Effect of modeling assumptions on the earthquake-induced losses and collapse risk of steel-frame buildings with special concentrically braced frames. ASCE Journal of Structural Engineering 2017b; 143(9): 04017116.

Ibarra, LF., Medina, RA., and Krawinkler, H. Hysteretic models that incorporate strength and stiffness deterioration. Earthquake Engineering \& Structural Dynamics 2005; 34(12), 1489-1511. 
Inamasu, H., Kanvinde, AM., and Lignos, DG. Seismic stability of wide-flange steel columns interacting with embedded column base connections. ASCE Journal of Structural Engineering 2019a; 145(12): 04019151.

Inamasu, H., Sousa, A. A., Güell, G., and Lignos, D. G. Exposed column base connections for minimizing earthquakeinduced residual deformations in steel moment-resisting frames. Proc., of the Society for Earthquake and Civil Engineering Dynamics (SECED) Conference 2019b, Greenwich, London.

Ioannou, I., Aspinall, W., Rush, D., Bisby, L., and Rossetto, T. Expert judgment-based fragility assessment of reinforced concrete buildings exposed to fire. Reliability Engineering \& System Safety 2017; 167, 105-127.

Iwata, Y., Sugimoto, H., and Kuguamura, H. Reparability limit of steel structural buildings based on the actual data of the hyogoken-nanbu earthquake. Proc., $38^{\text {th }}$ Joint Panel Meeting: Wind and Seismic effects, Gaithersburg, Maryland $2006 ; 23-32$

Jaiswal, K. S., Aspinall, W. P., Perkins, D., Wald, D., and Porter, K. A. Use of expert judgment elicitation to estimate seismic vulnerability of selected building types. Proc., $15^{\text {th }}$ World Conference on Earthquake Engineering 2012 , Lisbon, Portugal.

Kazantzi, AK., and Vamvatsikos, D. Intensity measure selection for vulnerability studies of building classes. Earthquake Engineering \& Structural Dynamics 2015; 44(15), 2677-2694.

Kohrangi, M., Vamvatsikos, D., and Bazzurro, P. Implications of intensity measure selection for seismic loss assessment of 3-D buildings. Earthquake Spectra 2016; 32(4), 2167-2189.

Kolmogorov, A. Sulla determinazione empirica di una legge di distributione. Giornale dell' Instituto Italiano delgi Attuari (in Italian) 1933; 4, 1-11.

Kolwankar, S., Kanvinde, A., Kenawy, M., Lignos, DG., and Kunnath, SK. Simulating local buckling-induced softening in steel members using an equivalent nonlocal material model in displacement-based fiber elements. ASCE Journal of Structural Engineering 2018; 144(10), 04018192.

Krawinkler, H. Cyclic loading histories for seismic experimentation on structural components. Earthquake Spectra 1996; 12(1), 1-12.

Krawinkler, H., and Miranda, E. Performance-based earthquake engineering. Earthquake Engineering: From Engineering Seismology to Performance-Based Engineering 2004; 9, 9-59.

Latour, M., Rizzano, G., Santiago, A., and Simões da Silva, L. Experimental response of a low-yielding, self-centering, rocking column base joint with friction dampers. Soil Dynamics and Earthquake Engineering 2019; 116, $580-592$.

Lignos, DG., Hartloper, A., Elkady, A., Hamburger, R., and Deierlein, G. G. Proposed updates to the ASCE 41 nonlinear modeling parameters for wide-flange steel columns in support of performance-based seismic engineering. ASCE Journal of Structural Engineering 2019; 145(9): 04019083.

Lignos, DG., Hikino, T., Matsuoka, Y., and Nakashima, M. Collapse assessment of steel moment frames based on EDefense full-scale shake table collapse tests. ASCE Journal of Structural Engineering 2013; 139(1), 120-132.

Lignos, DG., and Krawinkler, H. Deterioration modeling of steel components in support of collapse prediction of steel moment frames under earthquake loading. ASCE Journal of Structural Engineering 2011; 137(11), 1291-1302.

Lignos, DG., Krawinkler, H., and Whittaker, AS. Prediction and validation of sidesway collapse of two scale models of a 4-story steel moment frame. Earthquake Engineering \& Structural Dynamics 2011; 40(7), 807-825.

Luco, N., and Bazzurro, P. Does amplitude scaling of ground motion records result in biased nonlinear structural drift responses?. Earthquake Engineering \& Structural Dynamics 2007, 36(13), 1813-1835. 
MacRae, GA., Urmson, CR., Walpole, WR., Moss, P., Hyde, K., and Clifton, C. Axial shortening of steel columns in buildings subjected to earthquakes. Bulletin of New Zealand Society for Earthquake Eng. 2009; 42(4), $275-287$.

McCormick, J., Aburano, H., Ikenaga, M., and Nakashima, M. Permissible residual deformation levels for building structures considering both safety and human elements. Proc., $14^{\text {th }}$ World Conference on Earthquake Engineering (WCEE) 2008; 12-17.

Mckenna, FT. Object-oriented finite element programming: Frameworks for analysis, algorithms and parallel computing. University of California, Berkeley, CA 1997; Ph.D thesis.

NILIM. Quick report of the field survey and the building damage by the 2016 kumamoto earthquake. National Institute for Land and Infrastructure Management, Lausanne, Switzerland 2016; Report No. 929.

Olarte, J., Dashti, S., and Liel, AB. Can ground densification improve seismic performance of the soil-foundationstructure system on liquefiable soils?. Earthquake Engineering \& Structural Dynamics 2018; 47(5), 1193-1211.

Ozkula, G., Harris, J., and Uang, CM. Observations from cyclic tests on deep, wide-flange beam-columns. AISC Engineering Journal 2017; 54(1), 45-61.

Pijaudier-Cabot, G., and Bažant, ZP. Nonlocal damage theory. Journal of Engineering Mechanics 1987; 113(10), 1512-1533.

Raghunandan, M., and Liel, AB. Effect of ground motion duration on earthquake-induced structural collapse. Structural Safety 2013; 41, 119-133.

Ramirez, CM., and Miranda, E. Significance of residual drifts in building earthquake loss estimation. Earthquake Engineering \& Structural Dynamics 2012; 41(11), 1477-1493.

Rodas, PT., Zareian, F., and Kanvinde, A. Rotational stiffness of deeply embedded column base connections. ASCE Journal of Structural Engineering 2017; 143(8): 04017064.

Ruiz-García, J., and Miranda, E. Residual displacement ratios for assessment of existing structures. Earthquake Engineering \& Structural Dynamics 2006; 35(3), 315-336.

Ruiz-García, J., and Miranda, E. Inelastic displacement ratios for evaluation of structures built on soft soil sites. Earthquake Engineering \& Structural Dynamics 2006; 35(6), 679-694.

Saatcioglu, M., Tremblay, R., Mitchell, D., Ghobarah, A., Palermo, D., Simpson, R., Adebar, P., Ventura, C., and Hong, H. Performance of steel buildings and nonstructural elements during the 27 February 2010 Maule (Chile) earthquake. Canadian Journal of Civil Engineering 2013; 40(8), 722-734.

Shome, N., Cornell, C. A., Bazzurro, P., and Carballo, J. E. Earthquakes, records, and nonlinear responses. Earthquake Spectra 1998, 14(3), 469-500.

Smirnov, H. Sur les ecarts de la courbe de distribution empirique. Recueil Mathematique (in French) 1939; 6, 3-26.

Stevenson, JR., Becker, J., Cradock-Henry, N., Johal, S., Johnston, D., Orchiston, C., and Seville, E. Economic and social reconnaissance: Kaikoura earthquake 2016. Bulletin of the New Zealand Society for Earthquake Engineering 2017; 50(2), 346-355.

Suzuki, Y. Earthquake-induced collapse of steel moment resisting frames with conventional and high performance steel columns. McGill University, 2018; Ph.D. Thesis.

Suzuki, Y., and Lignos, DG. Large scale collapse experiments of wide-flange steel beam-columns. Proc., $8^{\text {th }}$ International Conference on Behavior of Steel Structures in Seismic Areas (STESSA), Shanghai, China 2015. 
Suzuki, Y., and Lignos, DG. Collapse behavior of steel columns as part of steel frame buildings: Experiments and numerical models. Proc., 16 ${ }^{\text {th }}$ World Conference on Earthquake Engineering (WCEE), Santiago, Chile 2017.

Suzuki, Y., and Lignos, DG. Development of collapse-consistent loading protocols for experimental testing of steel columns. Earthquake Engineering \& Structural Dynamics 2019 (accepted).

Vamvatsikos, D., and Cornell, CA. Incremental dynamic analysis. Earthquake Engineering \& Structural Dynamics 2002; 31(3), 491-514.

Wu, T-Y., El-Tawil, S., and McCormick, J. Seismic collapse response of steel moment frames with deep columns. ASCE Journal of Structural Engineering 2018; 144(9): 04018145.

Yue, S. The bivariate lognormal distribution for describing joint statistical properties of a multivariate storm event. Environmetrics (The International Environmetrics Society) 2002; 13(8), 811-819.

Zareian, F., and Medina, RA. A practical method for proper modeling of structural damping in inelastic plane structural systems. Computers \& structures 2010; 88(1), 45-53. 